\title{
Intraoperative surgical difficulties encountered during repeat caesarean section in a tertiary care centre in Northeast India
}

\author{
Korobi Morang*, Lithingo Lotha, Kiran R. Konda \\ Department of Obstetrics and Gynaecology, Assam Medical College and Hospital, Dibrugarh, Assam, India
}

Received: 22 September 2021

Accepted: 11 October 2021

\author{
*Correspondence: \\ Dr. Korobi Morang, \\ E-mail: korobimorang1@gmail.com
}

Copyright: $\odot$ the author(s), publisher and licensee Medip Academy. This is an open-access article distributed under the terms of the Creative Commons Attribution Non-Commercial License, which permits unrestricted non-commercial use, distribution, and reproduction in any medium, provided the original work is properly cited.

\begin{abstract}
Background: Caesarean section is the commonest obstetric operative procedure worldwide. The potential perioperative problems in repeat caesarean section include adhesions, increased blood loss, prolonged operative time, injuries to adjacent structures, hysterectomy etc. These increase with increase in caesarean section number.

Methods: Hospital based observational study, conducted at Dept. of Obstetrics and Gynaecology, Assam Medical College, from July 2019 to June 2020 with the aim to study intraoperative difficulties encountered during repeat caesarean section. Cases were grouped into two main groups based on number of prior caesarean sections. A detailed history, clinical and intraoperative findings of all pregnant women undergoing repeat caesarean section were noted. Results were tabulated and analysed.

Results: Out of 400 women with prior caesarean section who underwent repeat caesarean. 321 had 1 prior caesarean and rest had 2. Among the cases cephalopelvic disproportion was the commonest $(43.25 \%)$ indication and obstructed labour was the least common $(0.25 \%)$. Common complications were adhesions $(38.25 \%)$, thinned lower uterine segment (27\%), advance bladder (19.50\%), uterine dehiscence (14.75\%), excess blood loss $(12.75 \%)$, extension of uterine incision $(8.25 \%)$, uterine rupture $(1 \%)$, placenta accrete $(0.75 \%)$, and bladder injury $(0.5 \%)$. Intraoperative complications like adhesions, uterine dehiscence, delivery and operating time were significantly higher in women with 2 prior caesarean section compared to 1 prior caesarean section $(\mathrm{p}<0.001)$.

Conclusions: Women with caesarean scar are at high risk in subsequent pregnancies particularly in a country like India where antenatal care is often neglected. Best technique to reduce multiple potential complications of repeat caesarean section is to reduce the rates of primary and repeat caesarean sections whenever possible.
\end{abstract}

Keywords: Intraoperative complications, Caesarean section

\section{INTRODUCTION}

Caesarean section is the most common obstetric operative procedure worldwide. Its development and application has saved the lives of countless mothers and infants. ${ }^{1}$ Women with caesarean section are more likely to undergo further caesarean section and are likely to suffer more obstetric complication in the subsequent pregnancy compared to women with vaginal delivery. ${ }^{2}$ Caesarean section has however evolved into one of the safest operative procedures with advancements in surgical techniques, anesthesia and patient care. ${ }^{3}$ In a woman with second and subsequent pregnancy with a uterine scar, it is important to understand the long term potential adverse consequences which are not generally perceived by a short sighted focus on the immediate decision concerning mode of delivery. ${ }^{1}$

When medically justified, maternal morbidity and mortality can be prevented by a caesarean section. However, there are no benefits from the procedure for the mother and the infant where it is not required. After a caesarean section, an obstetrician may face many 
perioperative complications like adhesions, increased blood loss, prolonged operative time, injuries to the adjacent structures, hysterectomy etc. And the risks of complications increase with increase in caesarean section number. ${ }^{4}$ Depending on the number of previous caesarean sections, the scarring and adhesion formation is known to increase major complication rate from $4.3 \%$ to $12.5 \%$. $^{5}$ Uterine scar rupture is one of the life threatening complications of a repeat caesarean section that may end up in hysterectomy. Considering the above facts, the present study was undertaken to evaluate the intraoperative surgical difficulties a surgeon may encounter in women undergoing repeat caesarean section.

\section{METHODS}

This hospital based observational study was carried out in the Department of Obstetrics and Gynaecology at Assam Medical College and Hospital, Dibrugarh for a period of one year from 1st July 2019 to 30th June 2020 to assess the intra operative difficulties encountered in a repeat caesarean section and management modalities of the difficulties encountered during repeat caesarean section.

All pregnant women who had a previously delivered by caesarean section and presented to our department in the present pregnancy were considered for the study. A sample size of 400 was calculated considering $95 \%$ confidence interval with a margin of error correction of $5 \%$ and taking the findings of the study by Somani et al as reference. 6

All women underwent detailed history taking and clinical examination. Obstetric and pelvic examination were done and findings noted. Scar was palpated for tenderness. In case of floating head, Muller Kerr method was performed for assessment of CPD in women at or near term.

Relevant laboratory investigations were sent as per hospital protocol. USG was done in all women to assess fetal maturity, amount of liquor, placental position and thickness of scar.

Women were categorized on the basis of the number of caesarean deliveries that they had undergone (1 and 2). The intra-operative complications were noted and then compared with respect to adhesions, haemorrhage, extension of tears over uterus, injury to bladder, scar dehiscence, uterine rupture, need for hysterectomy etc. All the intra-operative complications were managed promptly. In rare circumstances, caesarean hysterectomy was decided when all the measures to preserve the uterus seemed to have failed like in cases of placenta accreta or uterine rupture.

The time taken to deliver the baby from the time of skin incision (delivery time), and the operating time (defined as skin incision to skin closure) were noted. Patients with uneventful post-operative period were discharged on the 5th post-operative day and were advised a mandatory hospital delivery in successive pregnancy.

The data was tabulated and a statistical analysis was performed using the computer program, Statistical package for social sciences (SPSS for Windows, version 20.0. Chicago, SPSS Inc) and Microsoft Excel 2010. Results on continuous measurements are presented as mean \pm standard deviation and are compared using student t test. Discrete data are expressed as number (\%) and are analysed using Chi square test. A probability value (p value) less than 0.05 was considered statistically significant.

\section{RESULTS}

Out of total 400 women with previous caesarean section, $321(80.25 \%)$ women were of previous one caesarean section and $79(19.75 \%)$ women were of previous two caesarean sections. Most of the women were in the age group between 26-39 years which accounted for 56.25\% followed by age group between 19-25 years which accounted for $29.75 \%$. 113 women (28.25\%) with previous caesarean section belonged to rural population and 287 women $(71.75 \%)$ belonged to urban population. Out of 400 women who had history of previous CS, maximum number of women (282) were second gravida that accounts for $70.50 \% .87$ women $(21.75 \%)$ were third gravida and 31 women $(7.75 \%)$ were $\geq$ fourth gravida. (Table 1).

Table 1: Maternal characteristics.

\begin{tabular}{|llll|}
\hline \multicolumn{5}{|c|}{$\begin{array}{l}\text { Previous caesarean } \\
\text { sections (C/S) }\end{array}$} & $\begin{array}{l}\text { Total } \\
\text { C/S 1 } \\
\text { n (\%) }\end{array}$ & $\begin{array}{l}\text { C/S 2 } \\
\text { n (\%) }\end{array}$ & \\
\hline Maternal age (years) & & \\
\hline $19-25$ & $105(32.71)$ & $14(17.72)$ & $119(29.75)$ \\
\hline $26-30$ & $180(56.07)$ & $45(56.96)$ & $225(56.25)$ \\
\hline $31-35$ & $34(10.59)$ & $18(22.78)$ & $52(13)$ \\
\hline$>35$ & $2(0.62)$ & $2(2.53)$ & $4(1)$ \\
\hline Mean \pm SD & $26.96 \pm 3.23$ & $28.54 \pm 3.41$ & $27.27 \pm 3.33$ \\
\hline Locality & & & \\
\hline Rural & $97(30.22)$ & $16(20.25)$ & $113(28.25)$ \\
\hline Urban & $224(69.78)$ & $63(79.75)$ & $287(71.75)$ \\
\hline Gravida & & & \\
\hline 2 & $282(87.85)$ & $0(0)$ & $282(70.50)$ \\
\hline 3 & $26(8.10)$ & $61(77.21)$ & $87(21.75)$ \\
\hline 4 or more & $13(4.05)$ & $18(22.78)$ & $31(7.75)$ \\
\hline
\end{tabular}

The commonest indication for performing a repeat caesarean section in current pregnancy was cephalopelvic disproportion $(43.25 \%)$. The second commonest being fetal distress $(21.25 \%)$. (Figure 1). 
Table 2: Relation between numbers of repeat LSCS with incidence of complications.

\begin{tabular}{|llll|}
\hline Number of previous C/S & Number $(\mathbf{n})$ & Complications & \% \\
\hline C/S 1 & 321 & $\mathbf{n}$ & 36.76 \\
\hline C/S 2 & 79 & 72 & 91.14 \\
\hline Total & 400 & 190 & 47.50 \\
\hline
\end{tabular}

Table 3: Association of number of previous caesarean sections with adhesions.

\begin{tabular}{|c|c|c|c|c|c|c|}
\hline \multirow{3}{*}{$\begin{array}{l}\text { No. of previous } \\
\text { C/S }\end{array}$} & \multirow{3}{*}{ No. (n) } & \multicolumn{4}{|c|}{ Adhesion } & \multirow{3}{*}{ P value } \\
\hline & & \multicolumn{2}{|c|}{ Present } & \multicolumn{2}{|c|}{ Absent } & \\
\hline & & $\mathbf{n}$ & $\%$ & $\mathbf{n}$ & $\%$ & \\
\hline 1 & 321 & 100 & 31.15 & 221 & 68.85 & \multirow{2}{*}{$<0.001$} \\
\hline 2 & 79 & 53 & 67.09 & 26 & 32.91 & \\
\hline
\end{tabular}

Table 4: Site and type of adhesions.

\begin{tabular}{|c|c|c|c|c|c|c|}
\hline & \multicolumn{4}{|c|}{ Previous caesarean sections (C/S) } & \multirow{2}{*}{\multicolumn{2}{|c|}{ Total }} \\
\hline & \multicolumn{2}{|c|}{ C/S 1} & \multicolumn{2}{|l|}{ C/S 2} & & \\
\hline & $\mathrm{n}=\mathbf{1 0 0}$ & $\%$ & $\mathrm{n}=53$ & $\%$ & $n=153$ & $\%$ \\
\hline \multicolumn{7}{|l|}{ Site of adhesion } \\
\hline Uterus-bladder & 44 & 44.00 & 26 & 49.06 & 70 & 45.75 \\
\hline Uterus-omentum & 20 & 20.00 & 12 & 22.64 & 32 & 20.92 \\
\hline Uterus-intestine & 2 & 2.00 & 0 & 0 & 2 & 1.31 \\
\hline Uterus-abdominal wall & 18 & 18.00 & 13 & 24.53 & 31 & 20.26 \\
\hline Uterus-adenexa & 4 & 4.00 & 0 & 0 & 4 & 2.61 \\
\hline Omentum-abdominal wall & 12 & 12.00 & 2 & 3.77 & 14 & 9.15 \\
\hline \multicolumn{7}{|l|}{ Type of adhesion } \\
\hline Filmy & 96 & 96 & 22 & 41.51 & 118 & 77.12 \\
\hline Dense & 4 & 4.00 & 31 & 58.49 & 35 & 22.88 \\
\hline Total & 100 & 100.00 & 53 & 100 & 153 & 100.00 \\
\hline
\end{tabular}

Table 5: Association of number of previous caesarean section with uterine dehiscence.

\begin{tabular}{|c|c|c|c|c|c|c|}
\hline \multirow{3}{*}{$\begin{array}{l}\text { Number of } \\
\text { previous C/S }\end{array}$} & \multirow{3}{*}{$\begin{array}{l}\text { Number } \\
\text { (n) }\end{array}$} & \multicolumn{4}{|c|}{ Uterine dehiscence } & \multirow{3}{*}{$P$ value } \\
\hline & & \multicolumn{2}{|l|}{ Present } & \multicolumn{2}{|c|}{ Absent } & \\
\hline & & $\mathbf{n}$ & $\%$ & $\mathbf{n}$ & $\%$ & \\
\hline 1 & 321 & 38 & 11.84 & 283 & 88.16 & $<0001$ \\
\hline 2 & 79 & 21 & 26.58 & 58 & 73.42 & $<0.001$ \\
\hline
\end{tabular}

Table 6: Delivery and operating time.

\begin{tabular}{|c|c|c|c|c|}
\hline \multirow{2}{*}{$\begin{array}{l}\text { Previous caesarean } \\
\text { sections (C/S) }\end{array}$} & \multirow{2}{*}{$\begin{array}{l}\text { Number } \\
\text { (n) }\end{array}$} & \multicolumn{2}{|c|}{ Delivery time (min) } & \multirow{2}{*}{ P value } \\
\hline & & Mean & \pm S.D. & \\
\hline C/S 1 & 321 & 4.93 & 0.57 & \multirow{2}{*}{$<0.001$} \\
\hline C/S 2 & 79 & 5.28 & 0.66 & \\
\hline Overall & 400 & 5.00 & 0.60 & \\
\hline \multirow{2}{*}{$\begin{array}{l}\text { Previous caesarean } \\
\text { sections (C/S) }\end{array}$} & \multirow{2}{*}{$\begin{array}{l}\text { Number } \\
\text { (n) }\end{array}$} & \multicolumn{2}{|c|}{ Operating time (min) } & \multirow{2}{*}{$P$ value } \\
\hline & & Mean & \pm S.D. & \\
\hline $\mathrm{C} / \mathrm{S} 1$ & 321 & 39.55 & 9.89 & \multirow{2}{*}{$<0.001$} \\
\hline $\mathrm{C} / \mathrm{S} 2$ & 79 & 48.54 & 10.10 & \\
\hline Overall & 400 & 41.33 & 10.55 & \\
\hline
\end{tabular}


Out of 400 women, $118(36.76 \%)$ were of previous 1 caesarean section and $72(91.14 \%)$ were of previous 2 caesarean section who had variety of intraoperative complications. This implies that the risk of complications increases with increasing number of caesarean section. (Table 2). The commonest complication encountered was intra-peritoneal adhesions of varied types which accounted for $31.15 \%$ in women with previous $1 \mathrm{CS}$ and $67.09 \%$ in women with previous $2 \mathrm{CS}$.

\section{Table 7: Adhesions.}

\begin{tabular}{|c|c|c|}
\hline Studies & $\begin{array}{l}\text { Adhesions in } \\
\text { previous } 1 \text { CS }\end{array}$ & $\begin{array}{l}\text { Adhesions in } \\
\text { previous } 2 \text { CS }\end{array}$ \\
\hline Somani et $a l^{6}$ & $40.85 \%$ & $65.96 \%$ \\
\hline Joseph et al ${ }^{12}$ & $33 \%$ & $40 \%$ \\
\hline Khursheed et $a l^{15}$ & $22.8 \%$ & $35.5 \%$ \\
\hline Lyell ${ }^{4}$ & $46 \%$ & $65 \%$ \\
\hline Morales et $a l^{16}$ & $46 \%$ & $75 \%$ \\
\hline Tulandi et $a l^{17}$ & $24.4 \%$ & $42.8 \%$ \\
\hline Present study & $31.15 \%$ & $67.09 \%$ \\
\hline
\end{tabular}

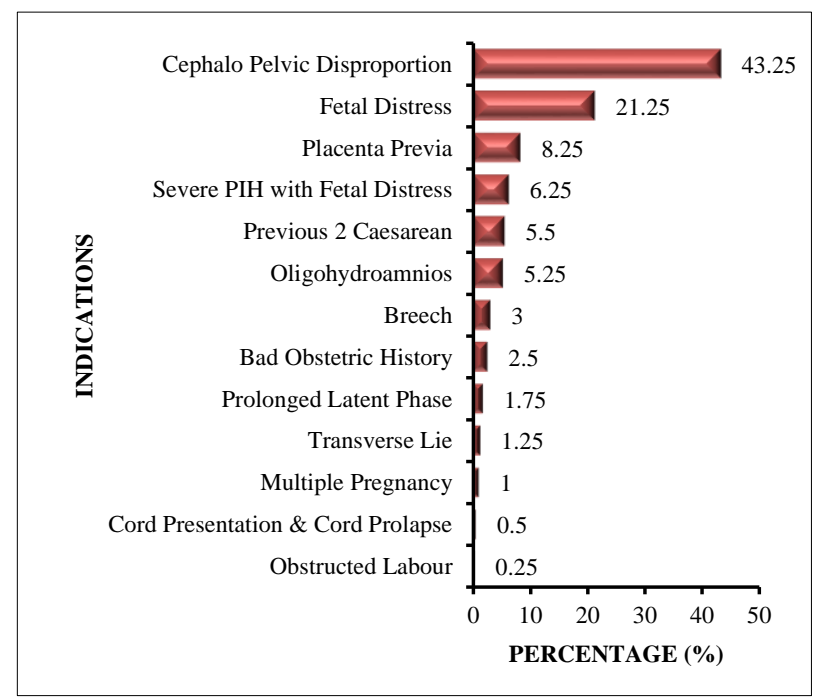

Figure 2: Indications of caesarean section in present pregnancy.

The urinary bladder was advanced (adherent at a higher level of anterior uterine wall) in $34.18 \%$ of the women with previous $2 \mathrm{CS}$ and $15.89 \%$ with previous $1 \mathrm{CS}$. The bladder was inadvertently injured in $2(2.53 \%)$ women with previous $2 \mathrm{CS}$. The incidence of thin Lower uterine segment (LUS) was found to be $25.23 \%$ in those with previous $1 \mathrm{CS}$ and $34.18 \%$ in those with previous $2 \mathrm{CS}$. This implies that as the number of CS increases, the chance of thin scar increases. Scar dehiscence (1 CS versus 2 CS $-11.84 \%$ versus $26.58 \%$ respectively) and scar rupture was seen in $5.06 \%$ women with previous $2 \mathrm{CS}$. Excess blood loss was noted in $10.90 \%$ versus $20.25 \%$ in women with with previous $1 \mathrm{CS}$ versus $2 \mathrm{CS}$ respectively. Placenta accreta was found in 2 women $(1.26 \%$ ) with previous 2 CS and 1 woman $(0.62 \%)$ with previous $1 \mathrm{CS}$. (Figure 2).
Incidence of adhesions was significantly higher with increased number of previous caesarean sections. 100 women $(31.15 \%)$ with previous 1 caesarean section and 53 women $(67.09 \%)$ with previous 2 caesarean had a variety of intra-peritoneal adhesions. (Table 3) The most common combination of adhesions was between uterus-bladder. Dense adhesions were found to be increased in successive repeat caesarean section. (Table 4).

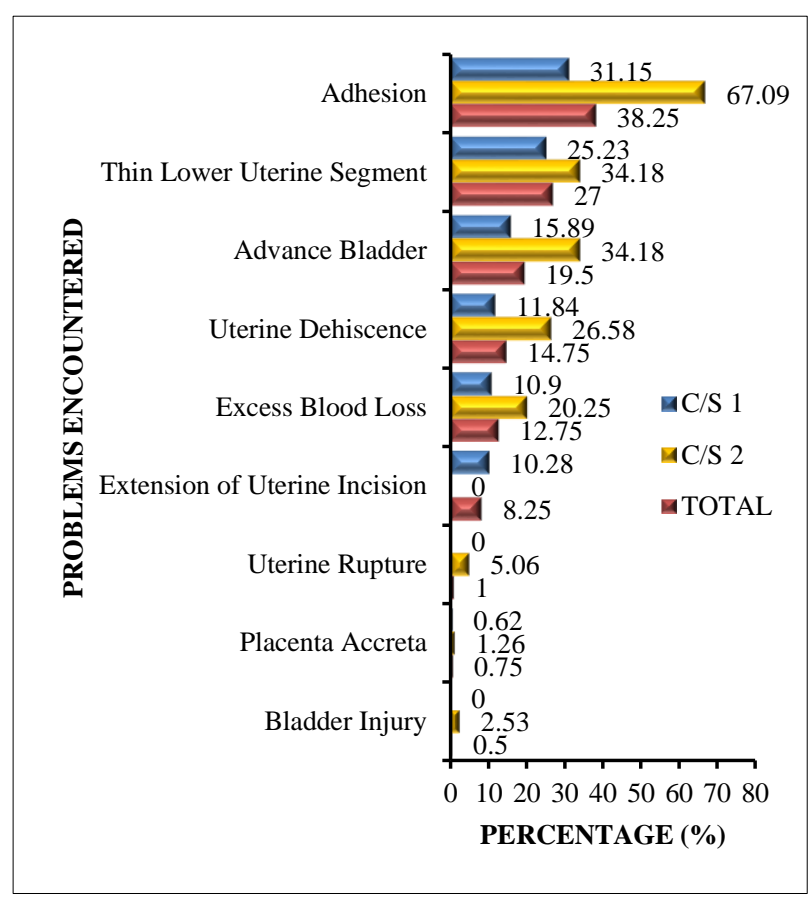

Figure 3: Intra-operative maternal morbidity during repeat caesarean section.

There was a significantly higher incidence of uterine dehiscence with increasing number of previous caesarean section. (Table 5). The delivery time and the operating time were significantly more in women with 2 previous caesarean sections. (Table 6).

Each woman was managed accordingly. In 86 (21.50\%) women only adhesiolysis was done. In 59 (14.75\%) women, on table scar dehiscence was diagnosed along with adhesions for which adhesiolysis with rent repair was done. In $2(0.50 \%)$ women adhesiolysis with extra bites at placental bed to control bleeding was carried out. In 2 women $(0.50 \%)$ adhesiolysis with inverted T-incision with extra bites at placental bed was done and in one woman $(0.25 \%)$ adhesiolysis with inverted T-incision was done. Likewise, adhesiolysis with extension suture was done in only 1 woman $(0.25 \%)$. In $33(8.25 \%)$ women, only extensions were sutured. In 1 woman $(0.25 \%)$ who had a through and through bladder injury during the opening of the abdomen, the bladder was repaired in two layers along with methylene blue dye instillation and continuous catheterization for 14 days. Caesarean hysterectomy had to be done in $1 \%$ women for placenta accreta and rupture uterus. 


\section{DISCUSSION}

In our observational study done over a period of one year, 400 pregnant women at or near term with previous caesarean section attending the labor room of Assam Medical College and Hospital were analyzed for the presence of intra-operative surgical difficulties encountered by the surgeon during repeat caesarean section.

Of the 400 women, 321 women $(80.25 \%)$ were of previous 1 caesarean section and 79 women $(19.75 \%)$ were of previous 2 caesarean sections. This is comparable with studies of Singh et al with $85 \%$ and $13 \%$ of previous 1 and 2 caesarean sections respectively and Sinha et al with $81.25 \%$ and $17.5 \%$ of previous 1 and 2 caesarean sections respectively. ${ }^{7,8}$

Analysis of the age of the patients showed that most of the patients $(86 \%)$ with repeat caesarean section were in the age group of 19-30 years. Youngest was 19 years of age with previous 1 caesarean section done for Cephalopelvic disproportion (CPD) 1 year back. Eldest was 36 years of age and she was G5P2L2A2 with previous 2 caesarean section. The present study is in accordance with the studies by Poovathi et al and Sheela et al where $80 \%$ and $68.9 \%$ of cases fall in age group of 21-30 years respectively., 9

The most common indication for performing a repeat caesarean section was cephalopelvic disproportion $(43.25 \%)$ followed by fetal distress $(21.25 \%)$, the second most common indication. This was comparable to a similar study conducted by Poovathi et al where majority of patients had undergone repeat caesarean section for cephalopelvic disproportion (50\%) and fetal distress (20\%). ${ }^{9}$ In a similar study by Ramkrishnarao et al, the most common indication of CS was cephalopelvic disproportion $(22.99 \%)$ followed by fetal distress $(19.51 \%){ }^{3}$

We found that the incidence of intra-operative complications increases with successive repeat caesarean section. Higher incidence of complication was observed in women with previous 2 caesarean section compared to previous 1 caesarean section $(91.14 \%$ and $36.76 \%$ respectively). Similarly, in a study by Lakshmi et al $81.8 \%$ and $37.8 \%$ of women with previous 2 and 1 repeat caesarean section respectively showed a variety of intraoperative complications. ${ }^{11}$ Similarly Joseph et al observed that complications in women with previous 2 and 1 were $84 \%$ and $51 \%$ repectively. ${ }^{12}$ In a study by Khursheed et al, the complication rate was $49.12 \%$ and $62.22 \%$ in women with previous 1 and 2 caesarean sections respectively. ${ }^{13}$

In the present study, adhesions accounted for $38.25 \%$ out of which $31.15 \%$ were of previous 1 caesarean section and $67.09 \%$ were of previous 2 caesarean. This was in accordance with other similar studies. (Table 7). These studies concluded that intra-peritoneal adhesions along with the extent and density increases with successive repeat caesarean section. In the present study, adhesions between uterus and bladder was comparatively very high $(45.75 \%)$ leading to difficulty in delivery of the head and prolongation of delivery and operating time. Adhesions between uterus-omentum was noticed in $20.92 \%$ and uterus-abdominal wall in $20.26 \%$. This was comparable with other similar studies by Singh et al and Somani et al. ${ }^{6,7}$

In our study, $12.75 \%$ women (1 CS versus $2 \mathrm{CS}-10.90 \%$ versus $20.25 \%$ ) had hemorrhages on table due to adhesions, abnormal placentation and extension of uterine incision. In a similar study by Somani et al, excess blood loss was noted in $11.86 \%$ women ( $1 \mathrm{CS}$ versus $2 \mathrm{CS}$ $7.04 \%$ versus $19.15 \%) .{ }^{6}$ Nisenblat et al concluded that 3 or more caesarean section was associated with significantly greater rate of hemorrhage (i.e blood loss $\geq 2$ litres of blood or transfusion $\geq 2$ litres of blood) than second delivery. ${ }^{5}$

In our study, there was no case of bladder injury in women with previous 1 caesarean section. Bladder was injured in 2 women with previous 2 caesarean section that accounted for $2.53 \%$. It is an uncommon complication associated with repeat caesarean section and is likely to be caused by adhesions. Somani et al observed only 1 case $(2.13 \%)$ of bladder injury in woman with previous 2 caesarean section, while, Khursheed et al found only $0.8 \%$ and $1.1 \%$ of bladder injury in previous 1 and 2 caesarean section respectively. ${ }^{6,13}$

In our study, $27 \%$ women $(25.23 \%$ and $34.18 \%$ of the women with previous 1 and 2 CS respectively) had thinned out lower uterine segment. In a similar study done by Somani et al $27.11 \%$ women had thinned out lower uterine segment out of which $21.13 \%$ women had previous $1 \mathrm{CS}$ and $36.17 \%$ women had previous 2 CS.6 Joseph et al found that the overall incidence of thinned lower uterine segment was $17 \%$ with $9.5 \%$ and $36 \%$ women with previous 1 and 2 CS respectively. ${ }^{12}$

In our study, $11.84 \%$ and $26.58 \%$ of women with previous 1 and 2 caesarean section had scar dehiscence respectively. In a similar study done by Somani et al, scar dehiscence was noted in $7.04 \%$ in previous $1 \mathrm{CS}$ and $31.91 \%$ in previous 2 CS.6 Jhajhria et al noticed scar dehiscence in $2 \%$ and $7 \%$ in women with previous 1 and 2 section respectively. ${ }^{14}$ Ramkrishnarao et al observed $6.62 \%$ of overall scar dehiscence in their study. ${ }^{3}$

Due to various intra-operative complications encountered during repeat caesarean section, it was observed that delivery and operating time was more in women with previous 2 caesarean section (mean delivery time of $5.28 \pm 0.66$ minutes and mean operating time of $48.54 \pm 10.10$ minutes) than in women with previous 1 caesarean section (mean delivery time of $4.93 \pm 0.57$ minutes and mean operating time of $39.55 \pm 9.89$ minutes).

Prompt management was done for each woman intraoperatively. The intra-peritoneal adhesions slowed down the surgical procedure as most of the cases were associated 
with excessive bleeding due to increase in raw surface area. Adhesiolysis was carried out in almost all the women with adhesions and at times also necessitated change of the obstetrician to a more experienced one for separating the dense adhesions. Adhesions accounted for $38.25 \%$ in the present study. Among them, some women also required adhesiolysis combined with rent repair $(14.75 \%)$, extra bites at placental bed $(0.50 \%)$, inverted $\mathrm{T}$-incision $(0.25 \%)$, inverted $\mathrm{T}$-incision with extra bites at placental bed $(0.50 \%)$ and higher incision $(0.50 \%)$. In a similar study by Jhajhria et al adhesions accounted for $36.5 \%$ and were managed by adhesiolysis with higher incision in some cases. ${ }^{14}$ Suturing of the uterine incision extension $(8.25 \%)$ and repairing of the bladder injury $(0.50 \%)$ was done by experienced hands to minimize the duration of surgery and thereby reducing maternal morbidity. Uterine scar rupture was seen in 4 women $(5.06 \%)$ with previous 2 CS. Need for obstetric hysterectomy was required in $1 \%$ of total women for uterine rupture and placenta accreta. This can be compared with studies by Sinha et al where incidence of hysterectomy was $3.75 \%$ and Somani et al where it was $2.13 \%$. $^{6,8}$

\section{CONCLUSION}

Women with caesarean scar are at high risk in subsequent pregnancies particularly in a country like India where antenatal care is often neglected. Best technique to reduce multiple potential complications of repeat caesarean section is to reduce the rates of primary and repeat caesarean sections whenever possible. Women should be counselled that repeat caesarean section are bound with intra-operative difficulties and complications. Whenever possible, keeping in mind the risks and difficulties, VBAC should be encouraged in women fulfilling the criteria for the procedure. Implementation of appropriate surgical techniques such as peritoneal closure should be considered in women who undergo caesarean delivery, particularly among women likely to have repeated surgical procedures. It is prudent to take senior obstetricians help for better surgical outcome.

\section{Funding: No funding sources}

Conflict of interest: None declared

Ethical approval: The study was approved by the Institutional Ethics Committee

\section{REFERENCES}

1. Baskett TF, Calder AA. Caesarean Section. In: Baskett TF, Calder AA, Arulkumaran S, editors. Munro Kerr's Operative Obstetrics. Saunders Elsevier. 2014;132-44.

2. Jacob L, Taskan S, Macharey G, Sechet I, Ziller V, Kostev K. Impact of caesarean section on mode of delivery, pregnancy-induced and pregnancy-associated disorders, and complications in the subsequent pregnancy in Germany. GMS Ger Med Sci. 2016;14(6):12-7.

3. Ramkrishnarao MA, Popat GU, Eknath BP, Panditrao SA. Intra-operative difficulties in repeat cesarean sections-A study of 287 cases. J Obs Gynecol India. 2008;58(6):507-10.

4. Lyell DJ. Adhesions and perioperative complications of repeat cesarean delivery. Am J Obstet Gynecol. 2011;205(6):S11-8.

5. Nisenblat V, Barak S, Griness OB, Degani S, Ohel G, Gonen R. Maternal complications associated with multiple cesarean deliveries. Obstet Gynecol. 2006;108(1):21-6.

6. Somani SS, Sudhir S, Somani SG. A study of intraoperative maternal morbidity after repeating caesarean section. Int J Reprod Contraception. Obstet Gynecol. 2017;7(1):291-6.

7. Singh P, Singh S. A study of per operative findings in cases with previous cesarean section. Int J Clin Obstet Gynaecol. 2019;3(1):66-8.

8. Sinha P, Gupta U, Singh J, Srivastava A, Chauhan S. Per operative findings in repeat cesarean section. Int $\mathrm{J}$ Reprod Contraception. Obstet Gynecol. 2016;5(4):10936.

9. Poovathi M, Suilharsini TS. Analysis of repeat LSCS in a tertiary care centre. Int J Reprod Contraception. Obstet Gynecol. 1964;7(5):1964.

10. Sheela WG, Chellatamizh M, Mohanambal M. Critical analysis of surgical difficulties and postoperative morbidities of caesarean deliveries: a rural teaching hospital experiences in silk city, South India. Int $\mathbf{J}$ Reprod Contraception, Obstet Gynecol. 2012;6(6):2566.

11. Lakshmi JV, Anuradha C, Rishitha M. Intra-operative complications in repeat cesarean sections. Int $\mathbf{J}$ Clin Obstet Gynaecol. 2020;4(2):144-9.

12. Joseph S, Gilvaz S. A Comparative Study on Intra Operative Problems during Primary versus Repeat Caesarean Sections. Sch J App Med Sci. 2016;4:303-10.

13. Khursheed F, Sirichand P, Jatoi N. Intra-operative Complications encountered in patients with repeat caesarean section. JLUMHS. 2009;8(01):76.

14. Jhajhria R, Meena P, Kosaraju Si. Comparative study of maternal morbidity in primary and repeat caesarean section. Int J Clin Obstet Gynaecol. 2018;2(2):69-74.

15. Khursheed F, Sirichand P, Jatoi N. Intraoperative complications encountered in patients with repeat cesarean section. J Liaquat Univ Med Heal Sci. 2009;8(1):76-9.

16. Morales KJ, Gordon MC, Bates Jr GW. Postcesarean delivery adhesions associated with delayed delivery of infant. Am J Obstet Gynecol. 2007;196(5):461-e1.

17. Tulandi T, Agdi M, Zarei A, Miner L, Sikirica V. Adhesion development and morbidity after repeat cesarean delivery. Am J Obstet Gynecol. 2009;201(1):56.e1-6.

Cite this article as: Morang K, Lotha L, Konda KR. Intraoperative surgical difficulties encountered during repeat caesarean section in a tertiary care centre in Northeast India. Int J Reprod Contracept Obstet Gynecol 2021;10:4144-9. 